\title{
Ensino de História nos anos finais do ensino fundamental: análise documental de seis estados brasileiros
}

(PUC-SP, São Paulo, SP)
Resumo: Como se caracteriza o ensino de História para os anos finais do ensino fundamental no Brasil? Eis a questão que norteia o presente artigo. Para tanto, apresenta-se inicialmente um breve histórico sobre o ensino de História no Brasil e em seguida são apresentadas algumas das características do ensino da História obtidas por meio de análises de documentos curriculares dos estados do Acre, Alagoas, Mato Grosso, Paraná, Pernambuco e São Paulo. Este artigo apresenta parte do que foi constatado durante a realização da pesquisa "Currículos para os anos finais do ensino fundamental: concepções, modos de implantação e usos", publicada pelo Centro de Estudos e Pesquisas em Educação, Cultura e Ação Comunitária (Cenpec, 2015) e utiliza como referencial teórico as contribuições de Bittencourt (2011).

Palavras-chave: Ensino de História. Anos finais do ensino fundamental. Análise de currículo. Documentos curriculares. 


\section{INTRODUÇÃO}

Faz-se necessário iniciar este artigo expondo inicialmente uma justificativa a respeito de seu título, isso porque desde 2006 a Lei de Diretrizes e Bases da Educação Brasileira (LDBEN, Lei 9.394/1996) estabelece que o ensino fundamental, um dos níveis da educação básica, deve ser de nove anos e, no que se refere à disciplina de História, ela está prevista para ser ministrada durante todo esse período (artigo 26 da LDBEN), sendo tal orientação corroborada pelas Diretrizes Curriculares Nacionais para a Educação Básica (DCNEB, Lei 12.796, de 2013).

Contudo, o atual ensino fundamental tem sua origem no ano de 1971, quando da implantação da Lei de Diretrizes e Bases da Educação (LDBEN) de nํ⒌692, que criou o ensino de primeiro grau no Brasil, por meio da junção dos até então denominados ensino primário e ensino ginasial. Porém, tal junção não se caracterizou como um "bloco" unitário, como se identifica no artigo 23 da Resolução no 4, de 13 de julho de 2010, que trata das Diretrizes Curriculares Nacionais:

O ensino fundamental com 9 (nove) anos de duração, de matrícula obrigatória para as crianças a partir dos 6 (seis) anos de idade, tem duas fases sequentes com características próprias, chamadas de anos iniciais, com 5 (cinco) anos de duração, em regra para estudantes de 6 (seis) a 10 (dez) anos de idade; e anos finais, com 4 (quatro) anos de duração, para os de 11 (onze) a 14 (quatorze) anos.

Portanto, sob a identificação de que, apesar de o ensino fundamental ser considerado como um dos níveis da educação básica, ele ainda está organizado em duas "fases": anos iniciais e anos finais. É possível identificar ainda que essas fases tendem a apresentar características bem distintas. Dentre elas, talvez a mais significativa seja a que se refere à formação docente, uma vez que para os anos iniciais é exigida dos professores a formação em Pedagogia e para os anos finais a exigência é que, além da licenciatura, o professor tenha formação específica para a disciplina que decida lecionar.

Dessa forma, retomando a questão da justificativa quanto ao título deste artigo, destaca-se que o objetivo deste é apresentar, de maneira sucinta, quais são as atuais características do ensino de História, para os anos finais do ensino fundamental, tendo como fonte a análise de documentos curriculares oficiais (vigentes no ano de 2015) de seis estados brasileiros: Acre, Alagoas, Mato Grosso, Paraná, Pernambuco e São Paulo. Tal análise é parte integrante da pesquisa desenvolvida pelo Centro de Estudos e Pesquisas em Educação, Cultura e Ação Comunitária (Cenpec) sob encomenda da Fundação Victor Civita 
(FCC), cujo título é "Currículos para os anos finais do ensino fundamental: concepções, modos de implantação e usos” (CENPEC, 2015). Coordenada pelo prof. Antônio Augusto Gomes Batista, essa pesquisa se desdobrou em três estudos que abrangeram a análise dos documentos curriculares dos estados brasileiros e do Distrito Federal, onde são apresentadas, com maior detalhamento, as demais justificativas para a dedicação de uma análise específica dos documentos curriculares referentes aos anos finais do ensino fundamental.

Assim, estando incumbida de descrever e analisar como a disciplina de História tem sido proposta nos documentos curriculares oficiais vigentes nos estados do Acre, Alagoas, Mato Grosso, Paraná, Pernambuco e São Paulo, é que, junto com uma equipe de pesquisadores das demais disciplinas, bem como com a equipe que compunha a coordenação da pesquisa, construiu-se um roteiro de análise específico para a realização deste estudo, cujo detalhamento pode ser consultado no Relatório Final da Pesquisa (CENPEC, 2015, p. 63-64).

\section{BREVE HISTÓRICO DA DISCIPLINA DE HISTÓRIA NO BRASIL}

A partir do momento em que o Estado brasileiro passou a ser independente de Portugal, identifica-se nos manuais destinados ao ensino do ler, escrever e contar, instruções quanto à possível utilização da Constituição do Império para as lições de leitura, buscando-se assim a inculcação moral e cívica junto aos cidadãos letrados que, com o passar dos séculos, só veio a se acentuar. Nesse período, foi considerado como obrigatório, além da leitura e da escrita, "noções de Gramática, princípios de Aritmética [...] e o ensino da doutrina religiosa" (BITTENCOURT, 2011, p. 62), passando a ser utilizada, para tanto, a descrição da História sagrada que dava ênfase à vida de santos, cabendo à História profana o caráter de opção, mesmo após o fim do vínculo entre a Igreja Católica e o Estado brasileiro.

Ao final do século XIX, com a abolição da escravatura, o advento da República e o processo de imigração, a sociedade brasileira mais urbanizada passou a tratar com maior efervescência o debate sobre cidadania e direitos civis e sociais e, consequentemente, a necessidade de se ampliar o atendimento nas escolas, uma vez que o domínio da leitura e da escrita podia significar a possibilidade de se obter o direito ao voto que, naquele momento, só era possível aos homens alfabetizados ${ }^{1}$ (artigo $1^{0}$ do Decreto nํㅜ 6, de 1890).

As mulheres brasileiras só puderam votar a partir de 1932 e os analfabetos só tiveram esse direito garantido, em caráter facultativo, a partir da Emenda Constitucional no 25 , 
No que se refere ao ensino de História, que passou a ser ensinada na escola primária a um número maior de cidadãos brasileiros, cabia conformar cada um deles ao seu respectivo papel social: diferenciando os "grandes homens", considerados aptos a governar a nação, dos demais, que deveriam sempre colaborar, com seu trabalho, para a manutenção, a ordem e o progresso desta mesma nação. Buscava-se, assim, propagar o patriotismo por meio do ensino da História. Identifica-se ainda que, para que tal objetivo fosse alcançado, o método de ensino utilizado era o da memorização: inicialmente com base no catecismo da Igreja Católica, o que significava que o ensino da História era pautado em perguntas e respostas que, posteriormente, veio a se consolidar sob a ideia de que "aprender História significava saber de cor nomes, fatos com suas datas, repetindo exatamente o que estava escrito no livro ou copiado nos cadernos" (BITTENCOURT, 2011, p. 67).

A partir dos anos 1930, com a criação do Ministério da Educação, o que se identifica é uma sedimentação ainda maior da ideia de se formar um cidadão patriota mediante a divulgação dos fatos históricos que envolviam os heróis nacionais (Tiradentes foi um deles!) e a ampliação do ensino da História do Brasil para o curso ginasial.

Aproximadamente duas décadas depois, surge entre os responsáveis pela educação no Brasil a defesa quanto à implementação dos Estudos Sociais mediante a incorporação das disciplinas de História, Geografia, Sociologia e Antropologia Cultural. Tal defesa ocorre diante da forte influência de estudos norte-americanos, de fundamentação psicológica, que acreditavam na necessidade de que tal implementação ocorresse, de forma progressiva, considerando a faixa etária dos alunos. Baseou-se, para tanto, nos denominados "círculos concêntricos", seguindo, por exemplo, a sequência: escola, bairro, cidade, país.

No tocante ao método de ensino para o nível secundário, também prevaleceu o método de memorização, tendo destaque o “método Zaba”, caracterizado pela utilização da "linha cronológica para auxiliar os alunos na resposta às perguntas sobre os principais acontecimentos de cada século" (BITTENCOURT, 2011, p. 85).

Faz-se necessário destacar aqui a importância do livro didático para a manutenção desse método, uma vez que por décadas “não existiam cursos de formação de professores secundários e os livros didáticos eram ferramentas

de 15 de maio de 1985. Essa situação se perpetua até os dias atuais, tendo por referência o inciso II do artigo 14ํ da Constituição Federal de 1988. 
fundamentais para o desenvolvimento da função docente" (BITTENCOURT, 2011, p. 88).

A partir da década de 1990, registra-se uma nova reforma curricular, que se pautou na formulação de documentos oficiais e leis específicas, dentre elas a promulgação da Lei de Diretrizes e Bases da Educação, de no 9.394, no ano de 1996 que, segundo Bittencourt (2011), foi inicialmente incentivada por questões externas pautadas, principalmente, na denominada "sociedade do conhecimento", que passou a exigir que os alunos tivessem "além de habilidades intelectuais mais complexas, formas de manejar informações provenientes de intenso sistema de meios de comunicação e de se organizar mais autônoma, individualizada e competitivamente nas relações de trabalho" (BITTENCOURT, 2011, p. 102).

Nesse período, o Brasil tinha como demanda as camadas populares que se encontravam fora da escola pública e que almejavam por democracia e, por outro lado, um projeto embasado na política neoliberal vigente, fatos que culminaram com a elaboração dos Parâmetros Curriculares Nacionais (PCN, 1998), que correspondem a um conjunto de textos elaborados pelo Ministério da Educação (MEC) e que descrevem os objetivos a serem alcançados pelos alunos no decorrer do processo de ensino e aprendizagem, passando a considerar a organização do ensino fundamental em quatro ciclos e, no que se refere aos conteúdos para a disciplina de História, elencou um eixo temático para cada um dos ciclos. Além disso, os PCN se caracterizam por suas orientações específicas quanto à metodologia a ser utilizada para o desenvolvimento dos eixos temáticos e, também, pelo estabelecimento de alguns critérios de avaliação.

No que se refere aos "conteúdos" da disciplina de História, elencados para anos finais do ensino fundamental, os PCN os definem tendo como referências dois grandes eixos temáticos: História das relações sociais, da cultura e do trabalho e História das representações e das relações de poder, que, por sua vez, se subdividem em quatro subtemas e que, por ventura, se desdobram em tópicos mais específicos.

Identifica-se ainda que, nos anos finais do século XX e iniciais do século XXI, novas demandas trouxeram alterações às leis sobre educação no país, com

A palavra "conteúdo" segue, neste artigo, a função ampla do termo, ou seja, contemplando de modo geral o que foi indicado como o que deve ser ensinado aos alunos ou por eles aprendido, a depender do caso, nos diferentes documentos analisados pela pesquisa "Currículos para os anos finais do ensino fundamental: concepções, modos de implantação e usos” (CENPEC, 2015, p. 36, nota 27). 
destaque para o ensino fundamental de nove anos (Lei $n-11.274$, de 6 de fevereiro de 2006) e a obrigatoriedade de que o ensino de História passasse a tratar da temática História e Cultura Afro-Brasileira e Indígena (Lei Federal no 11.645, de 10 de março de 2008). Tais demandas fizeram com que o Ministério da Educação (MEC), por meio do Conselho Nacional de Educação (CNE), publicasse, dentre outras orientações curriculares: as Diretrizes Curriculares Nacionais para a Educação das Relações Étnico-raciais e para o Ensino de História e Cultura Afro-brasileira e Africana na Educação Básica, no ano de 2004; as Diretrizes Curriculares Nacionais para a Educação Escolar Indígena, em 2012 e as Diretrizes Curriculares Nacionais para a Educação Básica, em 2013.

Passemos a nos ater às possibilidades de escolha dos "conteúdos" a ser trabalhados no ensino de História. Segundo Bittencourt (2011), é necessário estar atento à relação que deve existir entre produção historiográfica e ensino de História, de maneira a "assegurar uma aprendizagem efetiva e coerente" (p. 140), relação essa que só se concretiza mediante a formação contínua e de qualidade dos professores. Além disso, a autora chama a atenção sobre a necessidade de que haja um consenso quanto à seleção de conteúdos significativos, o que, segunda ela, pressupõe

\section{[...] certo consenso sobre a impossibilidade de ensinar "toda a história da humanidade" e a necessidade de atender os interesses das novas gerações, além de estar atento às condições de ensino. Estas condições são múltiplas e interferem nos critérios de seleção dos conteúdos, sendo preciso considerar desde a precariedade da rede pública escolar até o excesso de materiais didáticos e de informações disponiveis por intermédio dos diversos meios de comunicação, além de organizar os conteúdos dentro dos limites do "tempo pedagógico" destinado à disciplina pela grade curricular (BITTENCOURT, 2011, p. 138).}

O fato de não se poder ensinar "toda a história da humanidade", como bem destaca Bittencourt, direciona a obrigatoriedade quanto à realização da seleção de "conteúdos”, mas que conteúdos são esses? Quais são as justificativas apresentadas para tal seleção pelos documentos curriculares elaborados e oficialmente apresentados às redes de ensino públicas dos estados do Acre, Alagoas, Mato Grosso, Paraná, Pernambuco e São Paulo? Eis o que se descreve a seguir.

IDENTIDADES DO ENSINO DE HISTÓRIA EM SEIS ESTADOS BRASILEIROS

Como citado anteriormente, este artigo trata de apresentar algumas das principais características dos documentos curriculares de seis estados 
brasileiros. Trata-se, na verdade, de um pequeno recorte de uma importante pesquisa que se pautou em um grande volume documental, uma vez que abarcou, inicialmente, todos os estados brasileiros e o Distrito Federal com o objetivo de caracterizar não só o ensino de História, mas também promover uma ampla leitura do que se tem proposto como currículo pelas secretarias estaduais de Educação de todo o país. Produz, ainda, análises pormenorizadas das disciplinas: Português, Matemática, Geografia, Inglês, Arte, Educação Física e Ciências que, em geral, são ministradas para os anos finais do ensino fundamental.

No que tange à disciplina de História, a leitura de aproximadamente 10 mil páginas documentais resultou na elaboração de seis relatórios de análise que, juntos, contabilizam cerca de 125 laudas. Sendo assim, o que se segue são apenas algumas de suas principais características, não havendo, portanto, a possibilidade de se considerarem esgotadas outras tantas ponderações.

Acre e os "objetivos a serem alcançados"

No documento curricular de autoria da secretaria estadual do Acre, denominado Orientações Curriculares para o Ensino Fundamental: História (ACRE, 2010), o ensino de História é apresentado como sendo o que deve desenvolver nos alunos a capacidade de pensar historicamente, estabelecendo relações entre o passado e o presente de maneira a posicioná-los enquanto sujeitos de valores. Assim, sob tal objetivo, o que se apresenta inicialmente é a organização dos anos finais do ensino fundamental correspondendo aos $6^{\circ}$, $7^{\circ}, 8^{\circ}$ e e $9^{\circ}$ anos.

No que se referem à seleção dos “conteúdos", estes são propostos mediante os objetivos a serem alcançados pelos alunos, ao final de cada um dos quatro anos que compõem os anos finais do ensino fundamental. Além disso, para cada ano são considerados temas a serem trabalhados e um rol de "conteúdos" que tendem a apresentar fatos referentes à História Geral e à História do Brasil e que são denominados Conteúdos de diferentes tipos. Os temas propostos estão pautados nos PCN (1998) e tendem a permear os fatos históricos elencados, ano a ano, seguindo a ordem cronológica dos acontecimentos históricos, como se pode verificar no excerto a seguir, referente ao oitavo ( $8^{\circ} \stackrel{\circ}{)}$ ano: 


\begin{tabular}{|c|c|c|c|c|}
\hline ANO 8음 & Objetivos & $\begin{array}{l}\text { Conteúdos de } \\
\text { diferentes tipos }\end{array}$ & $\begin{array}{c}\text { Propostas de } \\
\text { atividade }\end{array}$ & Formas de avaliação \\
\hline & $\begin{array}{lr}\text { Conhecer r } & \text { as } \\
\text { principais } & \text { ideias } \\
\text { iluministas } & \text { e } \\
\text { sua } & \text { influência } \\
\text { na } & \text { organização } \\
\text { política } & \text { e } \\
\text { econômica } & \text { das } \\
\text { s o c i e d a d e s } \\
\text { em } \\
\text { r e a l i d a d e s } \\
\text { históricas. }\end{array}$ & \begin{tabular}{llr}
\multicolumn{1}{c}{ Conceito } & de \\
lluminismo & e \\
características & do \\
movimento iluminista \\
na & Filosofia e & na \\
Literatura. & \\
o & Identificação dos \\
principais autores e \\
obras do lluminismo. \\
[...]
\end{tabular} & $\begin{array}{lr}\text { Registro } & \text { no } \\
\text { caderno ou } & \text { outro } \\
\text { suporte } & \text { das } \\
\text { principais } & \text { ideias } \\
\text { estudadas em sala } \\
\text { de aula. } \\
\text { [...] }\end{array}$ & $\begin{array}{l}\text { Algumas propostas: } \\
\text { o Observação e } \\
\text { levantamento dos } \\
\text { conhecimentos prévios } \\
\text { do aluno sobre conceitos } \\
\text { como os de política, } \\
\text { liberdade, igualdade, } \\
\text { propriedade etc. por } \\
\text { meio de conversas e/ou } \\
\text { atividades relacionadas } \\
\text { ao cotidiano. } \\
\text { Contextos históricos. }\end{array}$ \\
\hline
\end{tabular}

Quadro 1 - Excerto do quadro de Referências Curriculares para História, do estado do Acre.

Fonte: Acre (2010, p. 48).

Ilustra-se, por meio desse excerto, que o documento acreano, além de apresentar a lista de objetivos a serem alcançados pelos alunos, atrela esses objetivos ao que se pode denominar lista de acontecimentos históricos, destacado como sendo os Conteúdos de diferentes tipos que, por sua vez, são complementados por uma lista de propostas de atividades, bem como de orientações quanto ao processo de avaliação que, como descrito no corpo do documento, deve ser contínua e somativa, considerando assim “o aluno em relação a ele mesmo, em relação ao que se espera dele e em relação aos demais colegas que tiveram as mesmas oportunidades escolares" (ACRE, 2010, p. 17).

\section{Alagoas e sua "carta de intenções"}

A análise documental de Alagoas revelou inicialmente a grande preocupação por parte do poder público daquele estado no que se refere aos resultados obtidos no Índice de Desenvolvimento da Educação Básica (Ideb): 
A educação básica de Alagoas tem apresentado indicadores educacionais muito abaixo do esperado no cenário educacional brasileiro, conforme pode ser comprovado pelos Indicadores de Desenvolvimento da Educação Básica - IDEB dos últimos anos. [...]

A reversão dessa situação requer um conjunto de mudanças estruturais de natureza técnica, administrativa, financeira e, principalmente, pedagógica, já que a qualidade da educação está diretamente vinculada à qualidade do processo de ensino-aprendizagem efetivado nas salas de aula (ALAGOAS, 2010, p. 7).

A partir de tal preocupação, o que se revela nos documentos é uma retrospectiva das políticas públicas adotadas até então com o intuito de justificar o quadro de "fracasso" escolar dos alagoanos. Contudo, os documentos tendem, a partir daí, a se pautar em leis para respaldar a organização do ensino fundamental.

Porém, não há explicitação, em nenhum dos documentos analisados, sobre quais são os objetivos do ensino de História para a rede estadual de Alagoas, havendo apenas a citação extraída das Diretrizes Curriculares Nacionais para a Educação Básica (DCNEB, 2013) em seu parágrafo 4ํㅜ, artigo 26, de que “o ensino da História do Brasil levará em conta as contribuições das diferentes culturas e etnias para a formação do povo brasileiro, especialmente das matrizes indígena, africana e europeia”.

E assim como não há explicitação sobre o porquê de se ensinar História, também não há detalhamento de "conteúdos", sendo apresentada apenas uma lista com 14 frases, sob o título de corresponderem às aprendizagens básicas a serem alcançadas ao final do ciclo II do ensino fundamental (ALAGOAS, 2010, p. 78).

Dessa forma, o que se pode afirmar mediante os documentos curriculares de Alagoas é de que estes se caracterizam, no que se refere ao ensino de História, por um “vácuo", uma vez que não foi possível identificar nenhum tipo de proposta efetiva, seja esta de permanência, de mudança, inovação ou tradicionalismo que paute a relação pedagógica no interior das salas de aula. 
Os vários documentos curriculares publicados pelo estado de Mato Grosso revelam a opção por uma organização do ensino fundamental baseada no que é descrito pelos documentos como sendo a "enturmação por idade", o que corresponde à existência de três ciclos, de três anos cada, a saber:

- $\quad$ - 1ํciclo: denominado Ciclo da Infância, devendo atender os alunos de 6 a 8 anos;

- $\quad$ - 2o ciclo: Ciclo da Pré-adolescência, para alunos de 9 a 11 anos;

- - 30 ciclo: Ciclo da Adolescência, para alunos de 12 a 14 anos, o que corresponde, assim, aos anos finais do ensino fundamental.

Merece destaque, também, na organização curricular no estado de Mato Grosso a opção pela interdisciplinaridade pautada no agrupamento das disciplinas em três diferentes áreas: Linguagem, em que estão agrupadas as disciplinas de Português, Arte, Educação Física e Língua Estrangeira; Ciências da Natureza, com o agrupamento das disciplinas de Matemática e Ciências, e a área de Ciências Humanas, na qual se agrupam História, Geografia e Educação Religiosa.

A partir dessa organização, a rede mato-grossense apresenta um exemplar específico com orientações para área de Ciências Humanas que recebeu 0 título de Área de Ciências Humanas (MATO GROSSO, 2010), de onde se pode extrair a definição quanto ao que se almeja mediante o ensino de História para os anos finais do ensino fundamental:

O ensino de História, diante da realidade apresentada na contemporaneidade, requer a elaboração de propostas a partir de conceitos próprios, sendo estes

fundamentais por aguçar o questionamento e a identificação das contradições presentes na sociedade, para que se possa superar e compreender alguns dos pressupostos da modernidade, como, por exemplo, a promoção do individualismo possessivo, articulado com a cultura consumista, que valoriza o ter em detrimento do ser. Sendo assim, observase a necessidade de trazer para discussão, dentro e fora da sala de aula, questões sobre o humanismo que possibilitem uma nova relação dos compromissos individuais e sociais com toda a humanidade (MATO GROSSO, 2010, p. 37, grifo do original).

Destaca-se assim a intenção de que os conhecimentos históricos sejam capazes de possibilitar aos alunos uma formação mais crítica mediante 0 individualismo e o consumismo presentes na sociedade contemporânea. Para tanto, o documento defende a importância da interdisciplinaridade, em que: "o currículo para o ensino de História precisa apropriar-se do diálogo interdisciplinar, assegurando ao estudante deste ciclo a possibilidade de abrir 
fronteiras, ressignificando os saberes e as práxis sociais" (MATO GROSSO, 2010, p. 38). Assim, o que passa a ser proposto é a organização interdisciplinar entre História, Geografia e Ensino Religioso, sendo este último de matrícula facultativa ao aluno. Interessante destacar que no documento Orientações Curriculares para as Ciências Humanas (s/d) se encontra em destaque a opção da secretaria estadual em oferecer a seus alunos o Ensino Religioso e não a Educação Religiosa, como está previsto na LDBEN vigente. Isso porque, segundo o documento, 0

Ensino Religioso, apesar de a LDB referenciá-lo numa perspectiva não-proselitista, ao longo de sua história, foi desenvolvido num modelo catequético cristão. Essas Orientações Curriculares entendem a "Educação Religiosa" fundamentada no trabalho com as pluralidades culturais-religiosas em suas manifestações simbólicas, significados, valores e práticas que fazem parte da cultura humana, presente em todos os povos, e em todas as épocas históricas (MATO GROSSO, s/d, p. 54).

Considerada a interdisciplinaridade proposta, o documento Orientações Curriculares para as Ciências Humanas (MATO GROSSO, 2010) apresenta uma seleção de "conteúdos" para o terceiro ciclo do ensino fundamental (anos finais) considerando inicialmente três eixos temáticos: Fronteiras e identidades, Trabalho, economia e sociedade e Natureza e sociedade. A partir desses eixos, são descritas quais capacidades devem ser desenvolvidas nos alunos e também uma lista dos denominados descritores, em que são identificadas orientações sobre "conteúdos" relacionados às disciplinas de História e Geografia. Segue excerto: 


\begin{tabular}{|c|c|c|}
\hline $\begin{array}{c}\text { Eixo } \\
\text { articulador }\end{array}$ & Capacidades & Descritores \\
\hline $\begin{array}{l}\text { Fronteiras e } \\
\text { Identidades }\end{array}$ & $\begin{array}{l}\text { - Construir conceitos de } \\
\text { identidade e grupo social, desenvolvendo } \\
\text { noções de respeito às diferenças; } \\
\text { - Reconhecer as formas e } \\
\text { regras de convívio social nos } \\
\text { diversos grupos que compõem a } \\
\text { sociedade; } \\
\text { [...] }\end{array}$ & $\begin{array}{l}\text { - Identificar os limites e as fronteiras } \\
\text { que separam os territórios nacionais; } \\
\text { - Distinguir os variados povos e } \\
\text { culturas existentes em diferentes } \\
\text { espacialidades do Brasil e do mundo; } \\
\text { - Concluir que alguns povos do mundo } \\
\text { não possuem soberania sobre o } \\
\text { território em que vivem; } \\
\text { [...] }\end{array}$ \\
\hline
\end{tabular}

Quadro 2 - Excerto do quadro de referências curriculares para História, Geografia e Ensino Religioso ( $3^{\circ}$ ciclo do ensino fundamental).

Fonte: Mato Grosso (2010, p. 46).

Identifica-se, portanto, que não é apresentado um rol de "conteúdos" específicos para a disciplina de História, fato que, se por um lado pode ser justificado pela opção pela denominada organização interdisciplinar, por outro, induz ao questionamento quanto à ausência da descrição do "como" deve ser dinâmica do processo de ensino e aprendizagem no cotidiano das escolas mato-grossenses.

Localizou-se, ainda, no documento Orientações Curriculares para a área de Ciências Humanas (MATO GROSSO, s/d), a descrição de categorias específicas de estudo que, segundo este documento, devem abranger todo o ensino fundamental:

[...] sociedade, tempo e espaço, trabalho, diversidades socioculturais e religiosas (gênero, sexualidades, religiosidades, geracionais e étnico-raciais), democracia, nação, paisagem, espaço geográfico e território, as quais permitem desenvolver o pensamento histórico e geográfico, ao longo dos anos do ensino fundamental organizado por Ciclos de Formação Humana (MATO GROSSO, s/d, p. 4).

A concepção de avaliação defendida nos documentos mato-grossenses é a avaliação diagnóstica, processual e cumulativa, por se tratar de uma avaliação emancipatória, isto é, que deixa de lado a classificação, seja em conceitos ou em notas. 0 documento defende ainda que o resultado de tais avaliações 
não deve assumir o caráter de apresentação por classificação, devendo ser evitada a utilização dos termos retenção e/ou aprovação. A avaliação contínua é assim considerada como a mais adequada mediante a opção pelos ciclos - denominados também Ciclos de Formação Humana - em que, segundo os documentos, o que deve ser considerado é a progressão dos alunos e não a possibilidade da existência de fracasso escolar.

Após a apresentação de toda uma defesa quanto à organização do ensino fundamental por ciclos, segue em destaque a seguinte afirmação:

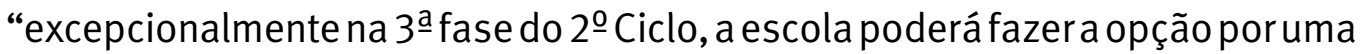
matriz globalizada ou por uma matriz organizada em área de conhecimento". Essa frase encontra-se no documento denominado Orientativo 2013 aos Ciclos de Formação Humana (MATO GROSSO, 2013, p. 5), em que também se descreve que caberá à escola optar por "uma matriz organizada em área de conhecimento com atribuição de disciplina”. Dessa forma, seguem alguns questionamentos: quais são as condições de excepcionalidade consideradas para a "quebra" da organização em ciclos, a partir do terceiro ano do segundo ciclo? Se caberá à escola optar pela organização em ciclos ou por área de conhecimento, que critérios devem ser seguidos quanto à seleção de "conteúdos"? As respostas para tais questões não foram obtidas quando da análise dos documentos curriculares mato-grossenses, mas acredita-se que são questões pertinentes, principalmente se considerarmos que não se referem a uma única escola, e sim a toda uma rede pública de ensino.

Paraná: uma aversão aos PCN?

De fato, os documentos curriculares oriundos da rede estadual do Paraná descrevem sua total aversão aos PCN e ao que se refere à disciplina de História:

Nos PCN, a disciplina de História foi apresentada de forma pragmática, com a função de resolver problemas imediatos e próximos ao aluno. Ressaltou-se a relação que o conhecimento deve ter com a vivência do educando, sobretudo no contexto do trabalho $e$ do exercício da cidadania. Essa perspectiva abriu espaço para uma visão presentista da História, porque não se ocupava em contextualizar os períodos históricos estudados. Além disso, muitos conceitos referenciais da disciplina foram preteridos em nome da aquisição de competências (PARANÁ, 2008, p. 43).

Sendo assim, a rede estadual paranaense declara que o ensino de História deve ser capaz de proporcionar aos alunos a compreensão da "realidade contemporânea e as implicações do passado em sua constituição" (PARANÁ, 2008, p. 74), de maneira a enfatizar, sempre que possível, a História local/nacional e, posteriormente a História Geral, enfatizando também 
os "conhecimentos historicamente sistematizados" (PARANÁ, 2008, p. 15). Pautados nessas afirmações, os documentos seguem a dinâmica da apresentação dos denominados "conteúdos estruturantes" para a disciplina de História sob a justificativa de estarem se pautando em uma "nova racionalidade não linear e temática” (PARANÁ, 2008, p. 45).

Os “conteúdos estruturantes” correspondem às Relações de trabalho; Relações de poder e Relações culturais. Identifica-se, contudo, que, apesar da crítica aos PCN, tais “conteúdos estruturantes” podem ser facilmente identificados como adaptações aos eixos temáticos apresentados pelos próprios PCN. No entanto, o documento Diretrizes Curriculares da Educação Básica: História (PARANÁ, 2008) justifica que sua opção curricular está pautada na proposta teórico-metodológica de Jörn Rüsen, que, por sua vez, descreve que os “conteúdos estruturantes" possuem a finalidade de que o ensino de História proporcione a "formação de um pensamento histórico a partir da produção do conhecimento" [e que proporcione aos alunos] "desenvolver uma consciência histórica que leve em conta as diversas práticas culturais dos sujeitos, sem o abandono do rigor do conhecimento histórico" (PARANÁ, 2008, p. 53).

A organização do ensino fundamental no estado do Paraná é anual, ou seja, os

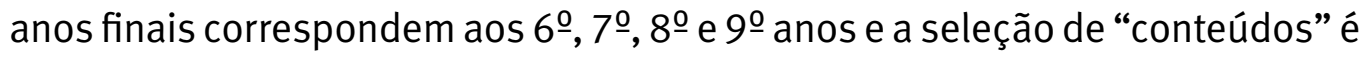
estabelecida a partir dos três "conteúdos estruturantes", sendo apresentados na forma de quadro os denominados "conteúdos básicos”, as abordagens metodológicas e também de avaliação, sendo esta última descrita, no documento analisado, como um processo composto pela avaliação diagnóstica (para identificar o que o aluno já sabe); avaliação formativa (realizada durante o processo de aprendizagem) e avaliação somativa (para apontar o quanto se conseguiu avançar a partir dos objetivos inicialmente propostos). Segue excerto de tal apresentação dos “conteúdos": 


\begin{tabular}{|c|c|c|c|}
\hline $\begin{array}{l}\text { Conteúdos } \\
\text { estruturantes }\end{array}$ & $\begin{array}{l}\text { Conteúdos } \\
\text { básicos }\end{array}$ & $\begin{array}{c}\text { Abordagem } \\
\text { teórico- } \\
\text { metodológica }\end{array}$ & Avaliação \\
\hline $\begin{array}{l}\text { - Relações de } \\
\text { trabalho } \\
\text { - Relações de } \\
\text { poder } \\
\text { - Relações } \\
\text { culturais }\end{array}$ & $\begin{array}{l}\text { História das } \\
\text { relações da } \\
\text { humanidade com } \\
\text { o trabalho. } \\
\text { O trabalho e a vida } \\
\text { em sociedade. } \\
\text { O trabalho e as } \\
\text { contradições da } \\
\text { modernidade. } \\
\text { Os trabalhadores } \\
\text { e as conquistas de } \\
\text { direito. }\end{array}$ & $\begin{array}{l}\text { - A abordagem } \\
\text { metodológica dos } \\
\text { conteúdos para o } \\
\text { ensino fundamental } \\
\text { parte da história } \\
\text { local/Brasil para o } \\
\text { mundo. } \\
\text { - Deverão ser } \\
\text { considerados os } \\
\text { contextos relativos } \\
\text { às histórias local, } \\
\text { da América Latina, } \\
\text { da África e da Ásia. }\end{array}$ & $\begin{array}{l}\text { Esta sugestão de conteúdos tem como } \\
\text { finalidade avaliar processualmente os } \\
\text { mundos do trabalho instituídos por um } \\
\text { processo histórico. } \\
\text { - Pretende perceber como os estudantes } \\
\text { compreendem: as relações dos mundos } \\
\text { do trabalho que estruturam as diversas } \\
\text { sociedades no tempo (sociedades } \\
\text { indígenas, trabalho coletivo, patriarcal, } \\
\text { escravocrata, servil e assalariado); as } \\
\text { contradições de classe na sociedade } \\
\text { capitalista; as lutas pelos direitos } \\
\text { trabalhistas. [...] }\end{array}$ \\
\hline
\end{tabular}

Quadro 3 - Excerto do quadro referência de conteúdos para $7^{\text {a }}$ série/8ํano - 0 Mundo do Trabalho e os Movimentos de Resistência.

Fonte: Paraná (2008, p. 90).

Complementarmente aos quadros de orientação curricular pautados nos "conteúdos estruturantes" há um documento denominado Caderno de Expectativas de Aprendizagem (PARANÁ, 2012) que estabelece, para cada ano, uma lista de expectativas de aprendizagem na qual se apresenta um detalhamento quanto ao "conteúdo" a ser desenvolvido em sala de aula. Segue exemplo:

Para o “conteúdo" básico História das relações da humanidade com o trabalho, são apresentadas as seguintes expectativas de aprendizagem para o $8^{\circ}$ ano:

- Compreenda como estavam organizados os primeiros grupos humanos no contexto da história dos povos sem escrita, bem como suas formas de trabalho;

- Compreenda a noção de escravismo antigo e as formas de resistência dos escravos na Antiguidade Clássica;

- Entenda a constituição das relações de trabalho no mundo medieval, enfatizando as obrigações servis e os ofícios realizados pelos servos;

- Compreenda como se deu o processo de transição do trabalho servil para o assalariado no final da Idade Média;

- Compreenda o processo histórico do sistema fabril europeu e a formação de novas formas de organização do trabalho como o controle do tempo e do saber do operário (PARANÁ, 2012, p. 64). 
Identifica-se, portanto, que, apesar de se manter a proposição de que o ensino de História deve ser pautado em temáticas (poder, trabalho e cultura), uma leitura mais detalhada das expectativas de aprendizagem revela a manutenção da apresentação de tais temáticas embasada na cronologia dos fatos históricos.

\section{Pernambuco: uma centena de expectativas de aprendizagem}

Segundo o documento Parâmetros Curriculares de História (PERNAMBUCO, 2013, p. 41), a rede estadual de educação de Pernambuco considera que ensinar História não se restringe à transmissão de conteúdos do passado, devendo este "contribuir para a formação do pensamento histórico nos estudantes" uma vez que, segundo o documento, é este pensamento histórico que proporciona o olhar ao passado para a compreensão dos problemas do presente e a formação de uma identidade social que impulsiona a reflexão e a tomada de decisão no agir cotidiano.

É, portanto, respaldado nesta definição sobre o ensino de História que o documento apresenta os denominados Núcleos Conceituais Comuns, que se subdividem em dois: núcleos conceituais e núcleos temáticos, sendo que, para cada um desses núcleos, "foi delineado um conjunto de expectativas de aprendizagem em História, ou seja, habilidades e conhecimentos, que se espera que os alunos sejam capazes de desenvolver e alcançar, nas diferentes etapas da educação básica” (PERNAMBUCO, 2013).

Para os anos finais do ensino fundamental, os núcleos temáticos são: 1) Sujeito histórico: identidade e diversidade; 2) Tempo; 3) Fontes históricas e, como núcleos temáticos, são elencados: 1) Relações de poder, cidadania e movimentos sociais; 2) Organizações políticas e conflitos: povos, nações, lutas, guerras, revoluções; 3) Natureza, terra e trabalho; 4) Sociedade, cotidiano, cultura e tecnologias; 5) Histórias de Pernambuco: sujeitos, práticas culturais e experiências coletivas.

É importante frisar que tais núcleos, aqui destacados como os que respaldam a seleção de "conteúdos" para os anos finais do ensino fundamental, na verdade são os mesmos que devem ser trabalhados durante toda a educação básica, ou seja, da educação infantil ao ensino médio. Tal ressalva se faz necessária uma vez que, ao se identificar o detalhamento das expectativas de aprendizagem para esses núcleos, o que se encontra é uma lista com 126 descrições de expectativas que permeiam toda a educação básica (há algumas exceções apenas para a educação infantil), sendo que, dessas, 125 
são elencadas para os quatro anos finais do ensino fundamental, variandose apenas a recomendação sobre a abordagem dessas expectativas, considerando a dinâmica do momento: momento 1) de familiarização do aluno com o conceito ou tema; momento 2) sedimentação do conceito ou tema; momento 3) aprofundamento do conceito ou tema.

A justificativa localizada para tal organização dos "conteúdos" para a disciplina de História é a de que

\begin{abstract}
[...] os professores em suas unidades escolares possam, num processo de discussão e construção coletiva, selecionar e organizar, de forma sistemática, os recortes temporais, os conteúdos e metodologias, estratégias e materiais, as fontes históricas que atendam às singularidades e demandas locais, na sua relação com a problemática da formação do cidadão, no contexto da sociedade global e multicultural em que vivemos (PERNAMBUCO, 2013, p. 44).
\end{abstract}

Fica destacada, portanto, a identificação de uma possível autonomia dos professores no que se refere às várias possibilidades de abordagem de uma mesma expectativa de aprendizagem, mas considera-se pertinente apontar que esta mesma autonomia pode, também, se caracterizar como a responsabilização dos docentes, seja pelos avanços obtidos ou pelos possíveis "insucessos" no processo de ensino e aprendizagem de toda uma rede. Isso porque, diante de um rol de 125 expectativas de aprendizagem, em que todas elas podem ser trabalhadas durante toda a educação básica e diante de séculos e séculos de História para ser estudados, que critérios os professores devem usar para tal seleção de "conteúdos" em cada uma das escolas que compõem a rede pernambucana de ensino? Considerar a realidade de sua escola? De sua sala de aula? A especificidade de seus alunos?

No que se refere ao processo de avaliação, todos os documentos analisados e, com maior ênfase, o documento Parâmetros para a Educação Básica do Estado de Pernambuco (PERNAMBUCO, 2012, p. 49) descreve que este deverá ser formativo, inclusivo e processual no sentido de avaliar não só o processo da aprendizagem, mas, também, do ensino.

São Paulo: muitos cadernos, muitos “conteúdos”

Entre os objetivos apresentados para a disciplina de História, os documentos do estado de São Paulo descrevem, inicialmente, que esta deve

favorecer a formação do estudante como cidadão, para que assuma formas de participação

social, política e atitudes críticas diante da realidade atual, aprendendo a discernir os

limites e as possibilidades de sua atuação, na permanência ou na transformação da

realidade histórica (SÃO PAULO, 2012, p. 26). 
Acrescenta-se ainda a esta definição a descrição de que "ensinar História significa avaliar criticamente os valores que desenham a sociedade, sem transformar as aulas em espaço para exercícios dogmáticos de militância partidária ou de raciocínio limitado à oposição estreita e maniqueísta entre bons e maus" (SÃO PAULO, 2012, p. 35).

Os "conteúdos" da disciplina de História são apresentados, inicialmente, no documento Currículo do Estado de São Paulo: Ciências Humanas e suas Tecnologias (SÃO PAULO, 2012). Neste documento são expressos, de maneira resumida, os denominados “tópicos disciplinares" (SÃO PAULO, 2012, p. 37) por meio de um Quadro de conteúdos e habilidades de História que abrange 23 páginas (da página 39 a 62), em que são apresentadas 190 habilidades a ser desenvolvidas nas séries que compõem os anos finais do ensino fundamental. No entanto, são nos denominados materiais de apoio, que correspondem aos Cadernos de Professores e de Alunos, em seus vários volumes, que, de fato, são organizados e detalhados os "conteúdos" da disciplina de História, pautados nos fatos históricos, ou seja, numa lista que abrange da Pré-História à Idade Contemporânea e que são denominados pelos próprios documentos de "conteúdos habituais" da disciplina. Os tais Cadernos de Apoio são distribuídos para alunos e professores de toda a rede paulistana, anualmente, em dois volumes, sendo, respectivamente, um para cada semestre.

Assim, sob a defesa de que é necessário proporcionar aos alunos o "patrimônio de conhecimentos acumulados ao longo do tempo" (SÃO PAULO, 2012, p. 35), os Cadernos de Apoio aos professores e alunos se caracterizam pela ênfase no "conteúdo" a ser desenvolvido semanalmente, uma vez que, para cada ano, são apresentados oito Situações de Aprendizagem por semestre que, se contabilizadas por bimestre, correspondem a uma Situação de Aprendizagem por semana. Identifica-se também que os "conteúdos" apresentados para a disciplina de História, para os anos finais do ensino fundamental, possuem como referência a ordem cronológica dos acontecimentos históricos.

Ainda com relação à seleção dos “conteúdos” de História, propostos por meio das Situações de Aprendizagem, constatou-se a caracterização de "aulas estanques" ou mesmo "aulas avulsas", no sentido de que, se um aluno não comparecer a uma semana de aulas, na próxima em que comparecer à escola não terá dificuldades em acompanhar a turma, uma vez que outro "conteúdo" será apresentado a partir de então.

Os documentos paulistanos analisados não apresentaram uma concepção explícita de avaliação. No entanto, a cada volume do Caderno de Apoio do 
Professor encontra-se enfatizada, em seu texto introdutório, a necessidade de que o processo de avaliação tenha por objetivo verificar a compreensão dos conteúdos conceituais da História.

\section{CONSIDERAÇÕES POSSÍVEIS}

É importante registrar que pesquisas realizadas por Bittencourt (2000) e Oliveira e Freitas (2012) também se debruçaram em analisar propostas curriculares da disciplina de História de diferentes secretarias estaduais de Educação de todo o país. Na primeira,

a intenção da pesquisadora era "identificar o alcance de tais propostas no que se refere às mudanças do conhecimento histórico escolar", transformações essas operadas a partir do processo de democratização pelo qual passara o país, que resultou até mesmo no retorno da disciplina História aos currículos do ensino fundamental (BITTENCOURT, 2000, apud OLIVEIRA; FREITAS, 2012).

E, na segunda, realizada por Oliveira e Freitas (2012, p. 271), o objetivo foi de "analisar as propostas curriculares produzidas para os anos finais do ensino fundamental, entre os anos 2007 e 2012, em 18 estados da Federação”, a saber: Acre, Alagoas, Amazonas, Bahia, Ceará, Espírito Santo, Goiás, Mato Grosso do Sul, Mato Grosso, Minas Gerais, Paraíba, Paraná, Pernambuco, Rio de Janeiro, Rio Grande do Sul, São Paulo, Sergipe e Tocantins. São apresentados como indicadores de sua análise as prescrições sobre o ensino de História referentes a

1. o lugar da história na formação do aluno (ou ideal de aluno a ser formado);

2. o sentido de conteúdo e a quantidade de expectativas anunciadas;

3. as prescrições em termos de conhecimentos e de habilidades (conhecimentos substantivos e meta-históricos); e

4. os usos dos diálogos entre as durações, e dos jogos de escala (OLIVEIRA; FREITAS, 2012, p. 271-272).

Em resumo, a pesquisa de Bittencourt (2000) identificou continuidades (ensino fundado no "tempo cronológico" e com foco pautado nos meios de produção) e também mudanças (introdução de uma "história problema”, tímidos estudos sobre a história e as culturas africanas e a quebra da convicção de que a Europa seria o "berço" da humanidade).

Em contrapartida, em 2012, Oliveira e Freitas identificaram uma maior ausência, nas propostas curriculares que analisaram, de uma teoria da história ou 
corrente ou escola, bem como a manutenção da definição de finalidades para o ensino de História, há tempos arraigadas: “formar identidades, cidadanias, compreender a realidade e os modos de produção do conhecimento histórico acadêmico" (OLIVEIRA; FREITAS, 2012, p. 295). É identificada uma pluralidade de concepções históricas e também a

ausência de progressão na maioria das propostas, a ênfase nos conhecimentos factuais e conceituais e procedimentais relacionados à pesquisa histórica, e a residual participação dos valores e conhecimentos linguísticos (OLIVEIRA; FREITAS, 2012, p. 295).

Além disso, Oliveira e Freitas (2012) identificaram a "presença equilibrada de todas as conhecidas e difundidas dimensões humanas, hierarquizadas em termos quantitativos na seguinte ordem: social, cultural, político e econômico" e uma baixa referência aos heroísmos individuais diante dos acontecimentos históricos. Identificaram também algumas incorporações de "conceitos e abordagens recentemente introduzidos na historiografia de ponta" e o predomínio da ênfase do espaço nacional em detrimento do transcontinental, global e continental (OLIVEIRA; FREITAS, 2012, p. 293-295).

No que se refere ao exposto neste artigo, frisa-se ser apenas uma pequena mostra do que se pôde identificar nos documentos curriculares analisados referentes aos estados de São Paulo, Pernambuco, Mato Grosso, Paraná, Acre e Alagoas, podendo ser destacado ainda que:

- Os estados de São Paulo, Pernambuco e Acre mantêm referências aos Parâmetros Curriculares Nacionais (PCN) quanto aos eixos temáticos, de maneira a adaptá-los quanto aos "conteúdos" a serem apresentados aos alunos no decorrer dos anos finais do ensino fundamental. Destacase, no entanto, a questão da nomenclatura que esses "conteúdos" recebem em cada um dos estados: em São Paulo, tais “conteúdos” são denominados habilidades a serem desenvolvidas; em Pernambuco, são as expectativas de aprendizagem e no Acre, estes são elencados sob a referência de serem objetivos a se alcançar. Nos documentos curriculares do estado do Paraná, onde foram identificadas explícitas críticas aos PCN, tais "conteúdos" são denominados "conteúdos estruturantes", enquanto que no estado de Mato Grosso o que se identificou foi uma lista com 14 objetivos a serem alcançados como aprendizagens básicas ao final do 9ํano.

- No que se referem aos fundamentos teóricos apresentados pelos documentos desses estados e que embasam o objeto de ensino da História, identificou-se que, com exceção do estado de Alagoas, 
os demais estados apresentaram referências aos debates mais contemporâneos sobre o estudo da História, havendo referências explícitas à contribuição da Escola do Annales, da Nova História, da Nova História Cultural e aos próprios PCN. Cabe destaque ao estado do Paraná, que faz referência ao historiador alemão Jörn Rüsen, autor do artigo "Didática da História: passado, presente e perspectivas a partir do caso alemão". Contudo, os estados de São Paulo e do Acre não apresentam referências a tais debates contemporâneos.

- Quanto aos processos didáticos para o ensino do "conteúdo" de História, somente os estados do Acre e de Alagoas não apresentaram nenhuma explicitação sobre o assunto. Há destaque para o estado de São Paulo, por apresentar o que pode ser denominado como indicações exaustivas e sequenciadas de atividades de ensino, que se materializam nos cadernos de apoio direcionados aos professores e também aos alunos. Já no que tange à descrição explícita sobre a adoção de uma linha metodológica para o trabalho em sala de aula, destaca-se o estado de Mato Grosso, que descreveu optar pelo sociointeracionismo, e o estado do Paraná, pelas denominadas “contranarrações” históricas, pautadas nos estudos de Jörn Rüsen.

- Considerada a possibilidade de articulação entre o universal e o local, identificou-se que os estados de Pernambuco, Mato Grosso, Paraná e Acre apresentam em seus documentos curriculares referências específicas para a disciplina de História, sobre "conteúdos" que se referem ao contexto local (estado, grande região, regiões do estado, inserção da escola nas comunidades). Cabe destaque ao estado de Pernambuco, que apresenta o eixo temático Histórias de Pernambuco: sujeitos, práticas culturais e experiências coletivas, a ser desenvolvido em toda a educação básica e, sob a ênfase contrária, ou seja, por apresentar tal articulação de maneira bastante pontual, encontra-se o estado do Acre, que descreve a questão local como "conteúdo" apenas para o último ano do ciclo II do ensino fundamental ( $9^{\circ}$ ano), sob orientação de que seja necessário abranger aspectos da História do Acre, desde a denominada Questão do Acre, no final do século XIX até a época atual. Nos estados de São Paulo e Alagoas não foi localizada, em seus documentos, nenhuma referência quanto ao contexto local.

- No que tange às possíveis modalidades de ensino: Educação de Alunos com Necessidades Educacionais Especiais (NEE); Educação de Jovens e Adultos (EJA); Educação no Campo; Educação de adolescente em medidas socioeducativas (internos); Quilombolas e Educação 
Indígena, identificou-se que os estados de São Paulo e Alagoas não apresentam nenhuma referência a essas modalidades; no estado de Pernambuco, há a citação quanto à Educação de Jovens e Adultos (EJA) e também quanto a alunos internos (em cumprimento de penas socioeducativas), sendo constatado ainda que o estado do Paraná produziu os denominados Cadernos de Orientação Pedagógica, especificamente para tais modalidades, que destacam a necessidade da realização, por parte dos docentes, de possíveis adaptações de "conteúdos", tendo por referência a grade curricular do ensino regular. No que se refere aos documentos regulares do estado de Mato Grosso, são citadas as modalidades de Educação de Jovens e Adultos (EJA); Educação de Alunos com Necessidades Educacionais Especiais (NEE); Educação no Campo; Quilombolas e Educação Indígena, que, por sua vez, passam a ser tratados, especificamente, nos documentos denominados Cadernos de Orientações Curriculares, que, no entanto, não se caracterizam como documentos de referência específica à disciplina de História, mas possuem o objetivo de chamar a atenção dos docentes, de todas as disciplinas, quanto à necessidade constante de se adequar, metodologicamente, o atendimento a cada uma dessas modalidades. Destaca-se, assim, mais sua ênfase às especificidades de cada modalidade do que pela promoção do diálogo com os denominados "conteúdos universais" da disciplina. Quanto ao estado do Paraná, os documentos regulares citam a Educação de Jovens e Adultos (EJA), a Educação no Campo e também a Educação Indígena, sendo localizados também cadernos com orientações pedagógicas específicas a essas modalidades, nos quais também são destacadas as necessidades de se adequar os "conteúdos universais" às especificidades de cada modalidade. No estado do Acre localizouse documento específico à EJA denominado A Política e Organização da Educação de Jovens e Adultos no Acre, em que, diferentemente dos demais estados, não são propostas adaptações, mas é apresentada uma organização específica, não só com relação aos "conteúdos”, mas também no que se refere à organização em módulos semestrais.

Destaca-se ainda que, quando considerada a possibilidade de que os estados tenham produzido documentos específicos à modalidade de alunos com Necessidades Educacionais Especiais (NEE), constata-se a total inexistência de referências ou menção a tal modalidade nos documentos curriculares dos seis estados analisados. 
Retomando-se o objetivo inicial deste artigo, que era o de apresentar, de maneira sucinta, quais são as atuais características do ensino de História para os anos finais do ensino fundamental, a partir da análise de documentos curriculares (vigentes em 2015) nos estados do Acre, Alagoas, Mato Grosso, Paraná, Pernambuco e São Paulo é que, aqui, destaco a crença de que a caracterização do ensino, seja ele de História ou de qualquer outra disciplina, tende a ser de grande valia para o atual contexto nacional, uma vez que se vivencia em todo o país o processo de debate quanto à elaboração de uma Base Nacional Comum Curricular.

No que se refere à disciplina de História, há de se pontuar que:

1) a seleção de “conteúdos” deve seguir finalidades bem específicas:

Como bem descreve Bittencourt (2011), mediante a impossibilidade de se "ensinar toda a história”, faz-se necessário expor aos alunos que a História é processual e que se pauta em conceitos, informações e valores que devem mobilizar diferentes formas de pensar:

Os conteúdos escolares podem ser variados [...] mas é preciso ter critérios que fundamentam sua escolha. A coerência de uma opção de conteúdos ocorre pela concepção de história, que por sua vez, fundamenta os conceitos. Estes, juntamente com as informações e as narrativas, constituem o conteúdo histórico escolar (BITTENCOURT, 2011, p. 172).

Para tanto, destaca-se a importância da formação de qualidade por parte dos docentes de História, para que estes estejam sempre atentos à crescente e diversificada produção historiográfica, podendo assim decidir ou ao menos debater com seus colegas de profissão quais conteúdos devem ser mantidos e quais devem ser introduzidos ou até mesmo abolidos.

2) a ideia de que se deve repudiar o que é denominado "tradicional" por meio da exaltação do que é novo precisa ser repensada:

Há pelo menos três décadas, o denominado “método tradicional” de ensino passou a ser veementemente criticado por muitos estudiosos no Brasil. Caracterizado primeiramente por impor a hierarquia de professores sobre alunos - o que faz deste último um mero receptor de informações -, o "método tradicional" se caracteriza pela ideia de que "ensinar é transmitir um conhecimento e aprender é repetir tais conhecimentos da maneira como foram transmitidos" (BITTENCOURT, 2011, p. 230). É, ainda, caracterizado por se pautar em aulas expositivas e pela utilização de lousa, giz e do livro didático. 
No entanto, mediante tal caracterização, Bittencourt (2011) chama a atenção de que não se deve confundir o método de ensino com a prática docente, que se refere mais especificamente ao que a autora denomina "tradição escolar" e que se fundamenta em dois aspectos:

O primeiro opõe-se à ideia de que, em educação, seja preciso sempre "inventar a roda", bastando verificar que muito do que se pensa ser novo já foi experimentado muitas outras vezes. $O$ outro [é que] muito do "tradicional" deve ser mantido, porque a prática escolar já comprovou que muitos conteúdos e métodos escolares tradicionais são importantes para a formação dos alunos e não convém serem abolidos ou descartados em nome do "novo". Assim, há que haver cuidado no processo de renovação escolar (BITTENCOURT, 2011, p. 229).

O cuidado a que se refere Bittencourt (2011) é justamente quanto à necessidade de se estar atento a situações em que a utilização das denominadas novas tecnologias, nas salas de aula, sejam interpretadas como formas de superar o “método tradicional”, situação esta que pode revelar uma condição inversa, de modo a serem apenas novos instrumentos para a manutenção da concepção de que o conhecimento deve ser simplesmente transmitido. Ao passo que, por outro lado, uma aula expositiva pode ser condutora, sim, da construção de conhecimento se, por exemplo, for proposto aos alunos um debate que considere prós e contras para um determinado assunto.

3) o tão temido processo de memorização necessita ser reavaliado:

Identificou-se que o método de ensino de História por memorização vem de longa data, porém, há que se ponderar que se faz necessário distinguir a memorização mecânica da memorização consciente: a memorização mecânica se caracteriza pelo “saber de cor”. Por outro lado, a memorização consciente tem por objetivo "desenvolver nos alunos a capacidade de memorizar acontecimentos, no caso da História, e referenciá-los no tempo e no espaço, para que, com base neles, se estabeleçam outras relações de aprendizado" (BITTENCOURT, 2011, p. 71). 


\section{The Teaching of History in Late Years of Primary Education: a Document Analysis of Six Brazilian States}

Abstract: How is the teaching of history characterized in the late years primary education in Brazil? This question guided the present article. To answer it, we first present a short history of the teaching of history in Brazil, and then describe a few characteristics of the teaching of history that we found by analyzing curriculum documents from the states of Acre, Alagoas, Mato Grosso, Paraná, Pernambuco and São Paulo. This article presents part of what was found in the study titled Currículos para os anos finais do ensino fundamental: concepções, modos de implantação e usos [Curricula for the late years of primary educations: conceptions, implementation modes, and uses], published by the Center for Studies and Research in Education, Culture and Community Action (Cenpec, 2015), and it builds on the contributions of Bittencourt (2011).

Keywords: History of education, late years of primary education, curriculum analysis, curriculum documents. 


\section{Enseñanza de Historia en los años finales de la enseñanza básica: análisis documental de seis estados brasileños}

Resumen: ¿Cómo se caracteriza la enseñanza de Historia en los años finales de la enseñanza básica en Brasil? Esta es la cuestión que guía el presente artículo. Así, se presenta inicialmente un breve historial sobre la enseñanza de Historia en Brasil y, a continuación, se presentan algunas de las características de la enseñanza de Historia obtenidas mediante el análisis de documentos curriculares de los estados de Acre, Alagoas, Mato Grosso, Paraná, Pernambuco y São Paulo. Este artículo presenta parte de lo que se constató durante la realización de la investigación Currículos para los años finales de la enseñanza básica: concepciones, modos de implantación y usos, publicada por el Centro de Estudios e Investigaciones en Educación, Cultura y Acción Comunitaria (Cenpec, 2015), y utiliza como referencia teórica las contribuciones de Bittencourt (2011).

Palabras clave: Enseñanza de Historia. Años finales de la enseñanza básica. Análisis de currículo. Documentos curriculares. 


\section{REFERÊNCIAS}

ACRE (Estado). Orientações Curriculares para o Ensino Fundamental: História. Rio Branco: SEE, 2010. (Série Cadernos de Orientação Curricular).

ALAGOAS (Estado). Referencial Curricular da Educação Básica para as escolas públicas de Alagoas. Maceió: Suped/SEE/AL, 2010.

BATISTA, Antônio Augusto Gomes. (Coord.). Currículos para os anos finais do ensino fundamental: concepções, modos de implantação e usos. Relatório final de pesquisa. São Paulo: Cenpec, 2015.

BITTENCOURT, Circe Maria Fernandes. Propostas curriculares de História: continuidades e transformações. In: BARRETO, Elba Siqueira de Sá (Org.). Os currículos do ensino fundamental para as escolas brasileiras. 2. ed. São Paulo: Fundação Carlos Chagas; Campinas (SP): Ed. Associados, 2000. p. 127161.

. Ensino de História: fundamentos e métodos. 4. ed. São Paulo: Cortez, 2011.

BRASIL. Lei de Diretrizes e Bases da Educação (LDBEN). Lei 5.692, de 1972. Brasília: Ministério da Educação, 1972.

. Lei de Diretrizes e Bases da Educação (LDBEN). Lei 9.394, de 1996. Brasília: Ministério da Educação, 1996.

. Parâmetros Curriculares Nacionais: História/Secretaria de Educação Fundamental. Brasília: MEC/SEF, 1998.

. Lei 10.639, de 9 de janeiro de 2003. Brasília: Ministério da Educação, 2003.

Diretrizes Curriculares Nacionais para a Educação das Relações Étnico-raciais e para o Ensino de História e Cultura Afro-brasileira e Africana na Educação Básica. Brasília: Ministério da Educação/Secad, 2004.

. Ensino de História e Cultura Afro-Brasileira e Indígena. Lei 1.1645, de 10 de março de 2008. Brasília: Ministério da Educação, 2008.

- Diretrizes Curriculares Nacionais Gerais para a Educação Básica:

Resolução nำ 4, de 13 de julho de 2010. Brasília: Ministério da Educação, 2010. 
Diretrizes Curriculares Nacionais para a Educação Escolar Indígena.

Brasília: Conselho Nacional de Educação/Câmara de Educação Básica, 2012.

Diretrizes Curriculares Nacionais da Educação Básica (DCNEB). Brasília: MEC, 2013.

MATO GROSSO (Estado). Orientações Curriculares - Área de Ciências Humanas: Educação Básica. Cuiabá: Seduc/MT, 2010.

Orientativo 2013: Ciclos de formação humana. Cuiabá: Seduc/MT, 2013.

Orientações Curriculares para a Educação Básica. Cuiabá: Seduc/ MT, s/d.

OLIVEIRA, M.; FREITAS, I. Currículos de História e expectativas de aprendizagem para os anos finais do ensino fundamental no Brasil (2007-2012). Revista História Hoje, v. 1, n. 1, p. 269-304, 2012.

PARANÁ (Estado). Diretrizes Curriculares da Educação Básica: História. Curitiba: Seed, 2008.

. Caderno de Expectativas de Aprendizagem. Curitiba: Seed, 2012.

PERNAMBUCO (Estado). Parâmetros para a Educação Básica do Estado de Pernambuco: Parâmetros Curriculares. Recife: SEE, 2012.

Parâmetros para a Educação Básica do Estado de Pernambuco: Parâmetros Curriculares de História. Ensino Fundamental e Médio. Recife: SEE, 2013.

SÃO PAULO (Estado). Currículo do Estado de São Paulo: Ciências Humanas e suas tecnologias. São Paulo: SE, 2012.

\section{Sobre a autora:}

Silmar Leila dos Santos é doutora e mestre em Educação pela Pontifícia Universidade Católica (PUC) de São Paulo, leciona a disciplina de História na Educação Básica e diversas disciplinas relacionadas à formação de professores na graduação e na pós-graduação. Atua também como pesquisadora e consultora na área de Currículo, organização escolar e política educacional. 
Atualmente exerce a função de pesquisadora e tutora no curso em EaD: Educação em Direitos Humanos (Parceria: Prefeitura Municipal de São Paulo e UFABC).

professorasilmarleila@gmail.com

Recebido em: janeiro de 2016

Aprovado em: abril de 2016 